\title{
Editorial
}

\section{Consumers and consumption: The opportunities and challenges of meeting consumers' aspirations}

In most developed countries of the world, there are some common characteristics that circumscribe consumer behaviour. For example, consumers can have nine or so distinct relationships with separate financial services companies to service basic banking, credit and store cards, savings, investments, pensions, life assurance and house and home insurance needs. This means that each provider has a relatively small 'share of each customer's wallet' and that most customers are 'multi-banked'. In addition, the behaviour of consumers in this sector is characterised by inertia, which refers to the widespread tendency of consumers to stay with the main provider of their financial services. Evidence for this state of affairs can be seen in high streets in the UK, for example, which continues to be dominated by the 'big four' universal banks, with a similar situation being replicated in other countries. It has been predicted for some time, however, that this characteristic inertia will gradually disintegrate $^{1}$ and that consumers will be more disposed to shop around and to switch providers, although it would appear that this change is occurring more slowly than initially foreseen. Whether the static behaviour of consumers begins to break down or not and levels of switching increase, the competitive and technological forces in the provision of retail financial services continue to have an impact on the way that financial services are provided and, ultimately, in the way that they are consumed.
An understanding and appreciation of consumption and the consumer in financial services is arguably more important than ever if providers of financial services are to rise to the competitive pressures building in the sector. The papers in this special issue, contributed by academics and practitioners, provide a worldwide perspective on recent developments in the understanding of consumers and consumption patterns, including valuable cultural dimensions. The theme of the papers could be summarised as 'something old' and 'something new' in that new technologies are investigated, but classic themes of marketing are revisited with a new spin such as perceived acceptability of failures and dissatisfaction. Recurrent concerns such as relationships, business-tobusiness relationships and service quality also appear in the papers for this special issue.

The slow diffusion of self-service banking technologies (SSBTs) into the mature consumer market necessitates research to understand better this growing section of the population and the diversity that exists within this market. Research conducted by Janelle McPhail and Gerard Fogarty analyses the $50+$ market, through a segmentation approach based on the level of use of self-service banking technologies in Australia. Three segments are identified: non-users, low users and medium-to-high users of SSBTs, profiled by frequency of use and demographic variables. The medium-to-high user 
segment embraces a range of SSBTs and uses credit cards to facilitate their financial activities. The research indicates that nonusers and some low users prefer the customary way of conducting transactions and enjoy the personal interaction with the bank employee, but that these two segments do have a moderate level of credit card use.

Srinivas Durvasula, Steven Lysonski, Subhash C. Mehta and Buck Peng Tang study relationships in the life insurance industry in Singapore. By linking the well-established constructs of satisfaction and value to behavioural outcomes such as repurchase and word of mouth (w-O-m), they reinforce the importance of $\mathrm{w}-\mathrm{O}-\mathrm{m}$ in customers' purchase decisions. ${ }^{2}$ Their study indicates that service quality has an indirect relationship with behavioural outcome measures via satisfaction and value. They also find that customer satisfaction is positively associated with repurchase intentions but that it is relatively weak when making recommendations. The additional value of their study is to base it in the life insurance industry where, owing to the complexity and credence qualities of the offering, wo-m might be thought to play a significant role.

The relationship between brokers and clients in the UK insurance industry is examined by Ahmed Beloucif, Bill Donaldson and Ugur Kazanci. The overriding concern in their study is an evaluation of the duration of the different stages in a relationship and characteristics that have an impact on the quality of a relationship. As in previous work, they find that trust, commitment and customer satisfaction positively influence relationship outcomes but not in equal measures and have a different impact at different stages. A model describing these stages, unique to this relationship, is tested but the impact of different characteristics is still inconclusive. Service quality, once more, is found to be a mediating variable with significant impact. Their results reveal that relationships need to be re-examined in an industry- and time-specific way.

In spite of research suggesting that services elicit greater dissatisfaction than products, service dissatisfaction has been less widely researched than product dissatisfaction and Tracy Panther and Jillian Dawes Farquhar base their investigation on the loyalty response to dissatisfaction. Their paper relates preliminary research study into customer dissatisfaction and loyalty, using two phases: to explore unsatisfactory experiences, and consumer decisions to switch or stay with the current provider. The study finds that the most commonly cited reason for staying with a financial services provider is the perceived costs involved in switching or, putting it more colloquially, 'the hassle factor'. Consumers' decisions about switching were also based on ties with the provider and perceptions of alternatives.

Technological advancement has challenged the providers of financial services so that the number of channels for consuming financial services has increased well beyond the traditional branch. Mari Suoranta and Minna Mattila explore the diffusion and adoption, in Finland, of one of the newest channels - mobile devices. Drawing on previous research that identified the typical characteristics of a potential adopter of electronic services, they explore some contradictory empirical findings generated by a mobile banking survey. The results of their study provide an indication of the characteristics of potential subsequent adopters of mobile banking, and of differences between user segments. They are able to comment on the influence of certain demographic characteristics and preferred communication mode of customers on the adoption and future usage of mobile banking services. 
Stefan Michel's paper presents a study of service failures of a bank and the impact of these failures on customer satisfaction and recommendation intention. In contrast to most other studies on this topic, this study uses a large, real-customer sample where the respondents describe a real failure incident, regardless of whether they complained about it. The study introduces the construct of 'acceptability' of service failures and relates it to the concept of a 'tolerance zone' for dissatisfaction. The impact of acceptability of service failure is explored with reference to satisfaction and recommendation intention, and is found to be both statistically significant and managerially relevant. The author, on the basis of his investigation, proposes a service failure pyramid as a managerial tool, which he then links to the idea of perceiving every service encounter as a 'moment of truth'.

The practitioner contributions begin with Raj Devasagayam and Jo DeMars' paper entitled 'Consumer perceptions of alternative dispute resolution mechanisms in financial transactions'. They examine consumer perceptions of choices of alternative dispute resolution mechanisms (ADRM) in resolving financial services and product dissatisfaction. Their results indicate that as the cash at risk increases, consumers indicate a preference for litigation over alternative forms of dispute resolution. The findings have strategic implications for strategy formulation in marketing of financial services and product as well as improving customer satisfaction through amicable resolutions of customer complaints.

The special issue concludes with an investigation into managing ethnic banking. From a professional perspective, this is one of the keys to success in an increasingly diverse marketplace. Premala Shanmuganathan, Merlin Stone and Bryan Foss describe the development of the ethnic banking market in the USA. This paper describes the main ethnic groups involved and how they manage their relationships with banks, whether as individuals, families or small businesses. It analyses how banks have responded to the ethnic marketing opportunity and then suggests which areas banks need to focus on in order to improve management of their ethnic customers.

The papers reflect enduring and innovative areas of research, often with a combination of both appearing in a single paper. These papers suggest that an understanding of consumer behaviour and consumption is as important, if not more important than ever, in the globalisation and 'technologicalisation' of banking services. Classical marketing concepts and constructs such as adoption of innovation, diffusion and relationships continue to play a valuable role within an increasingly diverse marketplace to assist in understanding consumer wants and needs and how services can be developed and delivered to meet evolving needs.

\section{REFERENCES}

1 Sweeney, T. (1999) 'The Death of Banking', British Bankers Association, London.

2 Gremler, D. and Brown, S. (1999) 'The loyalty ripple effect: Appreciating the full value of customers', International Journal of Service Industry Management, Vol 10, No. 3, pp. 271-291.

Jillian Dawes Farquhar Editorial Board Member Richard Lowrie Editorial Board Member April 2004

\section{Reviewers for the special issue on Consumers \& Consumption}

The following reviewers kindly lent their valuable expertise and time in reviewing the paper for this special issue:

David Harness - Leeds University

Dr Amanda Beatson - Aston University 
Dr Fran Brassington - Oxford Brookes University

Dr Jackie Clarke - Oxford Brookes University

Dr Jenny Rowley - Bangor University

Dr James Devlin - Nottingham University

Dr Julie Robson - Bournemouth University

Dr Kate Stewart - University of Ulster

Dr Tina Harrison - Edinburgh University

Georgina Whyatt - Oxford Brookes University

Jonathan Groucutt - Oxford Brookes University

Professor Angus Laing - Open University

Professor George Papaioannou - Frank G. Zarb School of Business

Professor Jeryl Whitelock - Salford University

Professor Peter Jones - University of Gloucester

Sally Harridge-March - Oxford Brookes University

Sally McKechnie - Nottingham University

Sarah Quinton - Oxford Brookes University

Theresa Smallbone - Oxford Brookes University

Tim Hughes - University of West of England

Tracy Panther - Oxford Brookes University

Bryan Foss - IBM

Professor Barry Howcroft - Loughborough University 